\title{
PERFIL DOS MORADORES E ASPECTOS ETNOPEDOLÓGICOS DE UM ASSENTAMENTO RURAL NO ESTADO DO RIO DE JANEIRO ${ }^{1}$
}

\author{
PROFILE OF THE RESIDENTS AND ETHNOPEDOLOGICAL ASPECTS OF A RURAL SETTLEMENT IN THE STATE OF RIO DE \\ JANEIRO
}

\section{RESUMO}

O objetivo do estudo foi definir o perfil dos assentados e dos lotes onde os mesmos residem, bem como analisar aspectos etnopedológicos no assentamento rural Fazenda do Salto, localizado no município de Barra Mansa - RJ. A definição do perfil do assentado foi estabelecida por meio da realização de entrevistas com base no Roteiro de Entrevista Semi Estruturada para avaliar o perfil dos moradores do assentamento, da propriedade, a percepção ambiental e agrícola dos assentados, bem como aspectos etnopedológicos. A amostragem se caracterizou por ser dependente dos sujeitos disponíveis, sendo realizadas 10 entrevistas com os moradores do assentamento. $\mathrm{O}$ perfil dos assentados e de seus lotes aponta para pessoas com idade superior a 50 anos, baixo nível de escolaridade, carentes de assistência técnica para auxiliar no desenvolvimento de suas atividades, baixo nível tecnológico aplicado em seus lotes, seja para a produção agrícola, seja para a pecuária, pouca ou nenhuma especialização e predominância de mão de obra familiar. Quanto à percepção dos aspectos etnopedológicos dos assentados ressalta-se a semelhança na descrição dos solos presentes no lote avaliado, em uma linguagem simplista e popular com aquela definida pela literatura científica e acadêmica.

Palavras-chave: Agricultura familiar. Reforma agrária. Percepção ambiental e agrícola. Etnopedologia.

\section{ABSTRACT}

The objective of this study was to define the profile of the residents and the lots where they live, as well as to analyze ethnopedological aspects in the Fazenda do Salto rural settlement, located in the municipality of Barra Mansa - RJ. The definition of the profile of the settler was established by means of interviews based on the Semi Structured Interview Roadmap to evaluate the profile of settlement dwellers, property, the environmental and agricultural perception of the settlers, as well as ethnopedological aspects. Sampling was characterized by being dependent on the available subjects, with 10 interviews with residents of the settlement. The profile of the settlers and their lots is aimed at people over 50 years of age, low level of education, lack of technical assistance to assist in the development of their activities, low technological level applied in their lots, be it for agricultural production, or for livestock, little or no specialization and predominance of family labor. As for the perception of the ethnopedological aspects of the settlers, the similarity in the description of the soils present in the lot evaluated is emphasized, in a simplistic and popular language with that defined by the scientific and academic literature.

Keywords: Family agriculture. Agrarian reform. Environmental and agricultural perception. Ethnopedology.

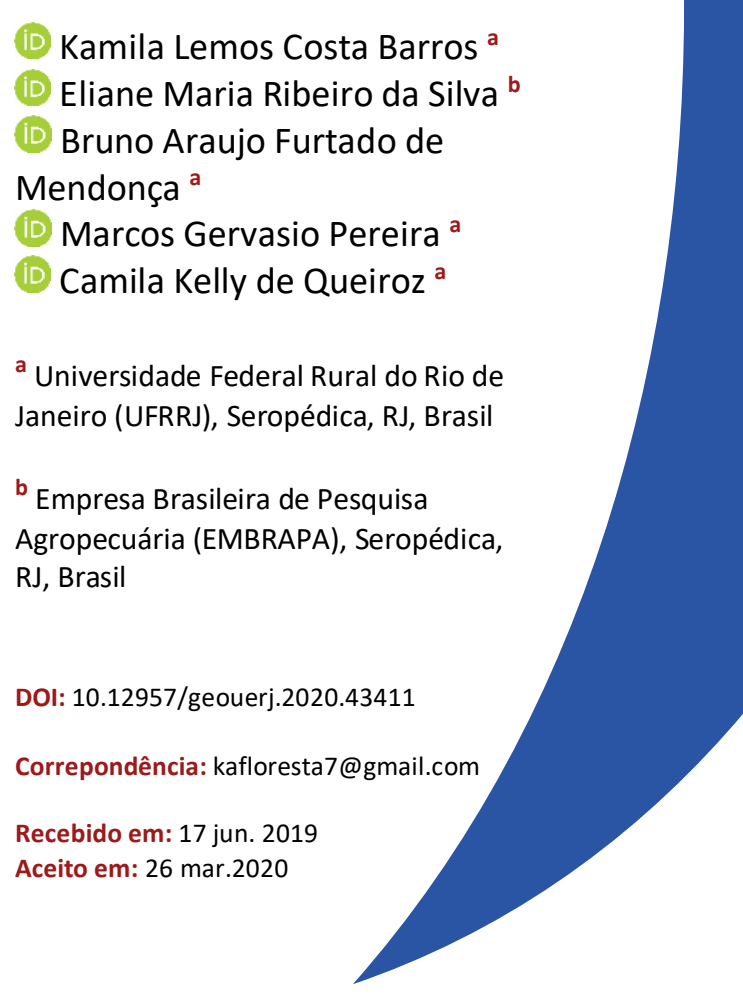

1 Artigo extraído de tese de doutorado finalizada pelo Programa de Pós-graduação em Ciências Ambientais e Florestais da Universidade Federal Rural do Rio de Janeiro-RJ. 


\section{INTRODUÇÃO}

O Estado assume toda a responsabilidade de viabilizar um assentamento, por ser ele o responsável por sua criação (LEITE et al. 2004). Após o processo sociopolítico de criação de um assentamento, Cardel e Oliveira (2013) mencionam outras etapas tão complexas quanto à inicial, tais como: o parcelamento da terra, a abertura de estradas, a seleção dos locais para a edificação das casas, a definição dos locais de instalação da rede elétrica rural, a destinação das áreas de uso social comum, a liberação de créditos para a construção de cercas, currais, escolas, igrejas, compra de animais e implementos agrícolas, até a fase dos plantios e das criações.

O assentamento rural é a alternativa de acesso a terra para aquelas famílias que procuram por moradia, para se estabelecer, produzir e sobreviver. As características desses assentamentos estão relacionadas à infraestrutura social e produtiva deficientes; alto nível de analfabetismo dos beneficiários das terras; insustentabilidade ambiental; em alguns casos, melhoria da segurança alimentar, com os cultivos direcionados à subsistência (BERGAMASCO, 1997; LIMA e LOPES, 2012).

O Brasil possui 9.374 assentamentos rurais, em uma área de 87,9 milhões de ha, com 972.289 famílias e no estado do Rio de Janeiro são 80 assentamentos rurais, 5.882 famílias assentadas e 177.638,43 ha delimitados pelo Instituto Nacional de Colonização e Reforma Agrária (INCRA) (INCRA, 2017).

Ao conhecer o perfil das propriedades rurais é possível gerar e transferir tecnologias adequadas para cada realidade vivenciada (FERNANDES e LIMA, 1991). Corroborando com essa ideia pode-se afirmar que diretamente atrelado ao perfil das propriedades rurais está o perfil do produtor, pois é ele quem dita os meios de se produzir e de aproveitar sua propriedade.

O termo "Etnopedologia" surgiu na década de 80, em comunidades agrícolas do México, em que foi aplicado para o estudo do conhecimento local no que diz respeito aos solos. Avaliar os conhecimentos relacionados aos solos, sua associação com recursos naturais e ainda estratégias desenvolvidas para se alcançar a produção são elementos de estudo da Etnopedologia. Para tanto, premissas básicas para desenvolvimento de trabalhos etnopedológicos resumem-se em metodologias participativas que promovem a inserção e participação direta da população envolvida na pesquisa (ARAÚJO et al. 2013).

Nesse sentido, o objetivo do trabalho foi definir o perfil dos moradores e dos lotes em que os mesmos residem, bem como analisar aspectos etnopedológicos no assentamento rural Fazenda do Salto, localizado no município de Barra Mansa - RJ, como suporte a avaliação da qualidade das terras e recomendações adequadas e viáveis para manejo. 


\section{MATERIAL E MÉTODOS}

A Fazenda do Salto, denominação do projeto de assentamento foi desapropriada em 17 de dezembro de 1996, sendo o assentamento criado em 17 de novembro de 1997, no modelo coletivo de produção, contudo, devido aos inúmeros conflitos entre as famílias assentadas e ocupações irregulares foi adotado o modelo individual (com a partilha da terra) (INCRA, 2012), que persiste até os dias atuais. $O$ assentamento rural Fazenda do Salto apresenta área de 944,45 hectares e abriga 40 famílias de trabalhadores rurais. Os lotes demarcados na área do assentamento variam de 0,50 a 29,05 ha. O assentamento está localizado no estado do Rio de Janeiro, município de Barra Mansa (INCRA, 2017), coordenadas geográficas UTM 572959 E, 7507866 S.

A população total do município de Barra Mansa, onde se localiza o assentamento é de 177.813 pessoas e a população rural equivale a 0,91\% da população total, sendo 1.620 pessoas (IBGE, 2010). Com base nos dados do Instituto Brasileiro de Geografia e Estatística (IBGE, 2016), referente à produção agrícola do município de Barra Mansa, a área plantada e/ou destinada à colheita das lavouras temporárias (cana-deaçúcar, feijão, mandioca, milho e tomate) e permanentes (banana) do município é de apenas 180 hectares; o efetivo de rebanho bovino do município é de 37.136 cabeças.

O clima predominante é o Cwa, com predominância de verões quentes (ALVARES, et al. 2013), com variações de temperatura entre 21 e $23^{\circ} \mathrm{C}$ e precipitação entre 1050 e $1300 \mathrm{~mm}$ (LUMBRERAS et al. 2003). $\mathrm{O}$ relevo predominante é constituído por colinas e morros (INEA, 2014). Considerando o levantamento semidetalhado elaborado por SOUZA (2008), na escala de 1:10.000, os solos que, predominantemente, ocorrem na área, são Argissolos Amarelos Distrófico típico, que recobrem 53,37\% da área do assentamento (504,14 ha) e $27 \%$ da área com a presença de Nitossolos Háplicos Distrófico Típico (255,85 ha).

Foi realizada uma reunião com a maioria dos moradores do assentamento Fazenda do Salto, em setembro de 2017. Após apresentação do projeto foi solicitado aos participantes da reunião que assinassem uma lista com seu nome e lote de residência, caso tivessem interesse em participar da pesquisa.

A partir dessa listagem foram realizadas visitas a campo, direcionadas àqueles interessados em participar da pesquisa. Com isso, a amostragem se caracterizou por ser dependente dos sujeitos disponíveis. As entrevistas foram realizadas por um único entrevistador, no período de 25/09/2017 a 23/11/2017. Das 40 famílias assentadas, 10 representantes dessas famílias, que se disponibilizaram a participar da pesquisa foram entrevistados.

As entrevistas semiestruturadas foram realizadas com moradores de origens diferentes, independente de gênero e idade (com exceção de menores de idade), ou ainda ocupação de posição dentro do grupo social. O roteiro de Entrevista Semiestruturada contemplou: Perfil dos entrevistados - caracterização dos sujeitos entrevistados, grau de instrução, faixa etária; Perfil das propriedades - caracterização da propriedade, 
atividades desenvolvidas, principais culturas implantadas, destino dos produtos cultivados; e Percepção agrícola e ambiental e aspectos etnopedológicos - análise do comportamento, das responsabilidades, dos interesses, das possibilidades de uso, das expectativas e da percepção relacionada ao meio ambiente, identificação da percepção dos principais problemas ambientais existentes, suas possíveis origens, efeitos e soluções, bem como conhecimentos sobre os solos, noções de uso e conservação dos mesmos.

A percepção ambiental relacionada aos solos presentes no assentamento foi comparada com a descrição e caracterização da Empresa Brasileira de Pesquisa Agropecuária - EMBRAPA: Árvore de conhecimento - Solos Tropicais (SANTOS et al. 2013).

As respostas obtidas durante as entrevistas foram tabuladas, transformadas em dados e organizadas em tabelas utilizando uma planilha de cálculo, e, posteriormente foram comparadas por meio de análises descritivas, com vistas à comparação, discussão e apresentação dos resultados.

\section{RESULTADOS E DISCUSSÃO}

Quanto aos entrevistados, metade deles é do gênero masculino e a outra metade, do gênero feminino. A maioria dos entrevistados (60\%) apresenta mais de 50 anos de idade, seguidos por moradores de 26 a 31 anos de idade $(20 \%)$.

A mão de obra familiar é predominante e restrita apenas ao casal que reside no lote, pois segundo relatos dos entrevistados, em alguns casos, os filhos não se interessam em se fixar na área, preferindo estudar e trabalhar nas cidades próximas. Dal Moro (2007) também observou esse padrão no tocante à postura dos filhos em um estudo realizado no Espírito Santo e afirma que a opção é a migração para a cidade ou em busca de novas possibilidades de trabalho ou de estudo, é vista por eles como uma forma de ascender socialmente, enquanto os pais permanecem no campo. Em contrapartida, Lopes e Carvalho (2015), verificaram que os jovens de um assentamento rural em Teresina - PI demonstraram o desejo de permanecer no assentamento, construindo projetos de vida no espaço em que moram, por considerar o campo como a alternativa mais viável para seus futuros.

Duas viúvas foram entrevistadas e são as responsáveis por dar sequência às atividades produtivas no lote, com auxílio de vizinhos ou filhos que retornam às suas origens devido ao desemprego. A mão de obra é um fator limitante que interfere diretamente na sobrevivência das famílias assentadas, principalmente quando se considera o envelhecimento da população assentada, problemas de saúde e o êxodo da juventude rural (DE GASPARI e KHATOUNIAN, 2016). 
A caracterização do sistema de produção é de agricultura familiar, com ênfase na subsistência e no comércio externo. A adoção de cultivos voltados para a subsistência, de acordo com Lima e Lopes (2012) promove maior segurança alimentar para os assentamentos, principalmente para aqueles estabelecidos há muitos anos. Para Rosanova e Ribeiro (2010), "a agricultura familiar não significa pobreza, muito menos miséria ou ignorância"; caracteriza-se por ser uma forma de produção em que o planejamento, gerência, decisões, a realização do trabalho e o controle financeiro são feitos pela família. As principais atividades desenvolvidas nos lotes são: produção de oleráceas (chuchu, jiló, abobrinha, quiabo, abóbora, pimenta, berinjela, cebola, brócolis, alface, couve), frutas (banana, maracujá, laranja e manga) e pecuária para produção de leite e corte.

Os produtores apresentam, comumente, baixo nível de escolaridade e renda e buscam diversificar suas atividades com vistas a aproveitar melhor a área da propriedade, bem como a mão de obra disponível, objetivando o aumento da renda. O nível de escolaridade dos entrevistados é em sua maioria, ensino fundamental incompleto, com exceções, para um com nível médio completo e outro com formação técnica em agropecuária, sendo ambos do sexo feminino e os mais jovens moradores entrevistados, tanto em idade, quanto em tempo de residência no assentamento.

Foi observado durante a realização das entrevistas e pelos relatos dos entrevistados, que o lote da moradora com maior grau de instrução tem servido como referência para os outros assentados, no que diz respeito à produção orgânica, bem como a aplicação de conhecimentos técnicos advindos de sua formação escolar, que promove melhor aproveitamento dos recursos e produção mais eficiente e sustentável como práticas de compostagem e adubação orgânica. Para Soares et al. (2013) aqueles produtores com maior nível escolar buscam maiores conhecimentos e capacitação, e nesses casos, investem mais em suas propriedades e atingem maior produtividade. Sosa et al. (2011) afirmam que um camponês acredita mais no que outro camponês diz do que um técnico da área. Os autores ressaltam que a disseminação do conhecimento desta forma, tornando o camponês o protagonista das ações na sua propriedade, é mais dinâmica e atinge muito mais produtores do que o conhecimento compartilhado de assistência técnica.

Dos entrevistados, 80\% residem no assentamento há mais de 15 anos. Ressalta-se que dentre esses, a maioria já residia nas terras antes mesmo da implantação do assentamento rural Fazenda do Salto. A maioria dos entrevistados residem em lotes que apresentam áreas superiores a 2 e inferiores a 20 hectares (INCRA, 2009). Ao considerar que 1 módulo fiscal no município de Barra Mansa possui dimensões de 26 hectares (INCRA, 2013), os lotes avaliados podem ser caracterizados como minifúndio ou pequena propriedade familiar, conforme definições no Estatuto da Terra, Lei n. 4.504, de 30 de novembro de 1964. Há de se ressaltar que a área útil dos lotes no assentamento Fazenda do Salto é ainda menor, haja vista a declividade do terreno em toda a extensão do assentamento que dificulta a implantação de atividades agrícolas. 
Em 20\% dos lotes participantes da pesquisa, a atividade principal é a pecuária, 40\% com predomínio de cultivos agrícolas e atividade mista em $40 \%$ dos lotes. Lima et al. (2009) afirmam que uma das principais limitações para o crescimento dos sistemas produtivos é a ausência de especialização nas atividades desenvolvidas ou pouca diversificação. Todavia, nos casos de pequenos produtores, a opção por diversificar as atividades da propriedade pode ser benéfica, pois, promove mais segurança no que se refere à comercialização dos produtos.

Em geral, a produção de oleráceas para subsistência é diversificada e utiliza pequenas áreas. Ainda assim, os assentados destinam uma área para alimentar os animais com o predomínio de pastagens. Ressaltase que essas áreas são pequenas para a manutenção e conservação das forragens (JÚNIOR et al. 2003), tendo em vista o pastejo com lotação contínua adotado pelos assentados, podendo colocar os assentados em situação de vulnerabilidade em épocas de estiagem, fazendo com que adotem alternativas de complementação de alimentação para o gado, como o uso do que eles denominam de "cevada", caracterizado como resíduo da indústria de produção de cervejas da região.

Quanto às instalações para a obtenção do leite foi verificado o baixo nível tecnológico dos sistemas produtivos, com a ordenha manual, uma vez que a maioria da produção é extensiva. O transporte do leite é feito até o ponto de entrega para o caminhão com tanque que armazena toda a produção do assentamento e encaminha para a cooperativa.

Parte da produção gerada no assentamento é destinada ao comércio externo, nas cidades circunvizinhas, como Quatis, Porto Real, Resende, Barra Mansa e Volta Redonda. A produção agrícola é destinada, basicamente às feiras, mercearias e locais de venda direta. Apenas um dos entrevistados produz, exclusivamente, para sua subsistência. Ressalta-se ainda, que ocorre também a comercialização de produtos dentro do próprio assentamento, entre as famílias assentadas, caracterizada por uma fonte de renda alternativa e importante para o sustento das famílias. Ao avaliar a comercialização de hortaliças de um assentamento no estado de São Paulo, De Gaspari e Khatounian (2016) verificaram que a venda direta dos produtos não interferiu na renda gerada para as famílias e a escolha da forma de comercialização esteve associada ao tamanho da família, em que as famílias com maior número de membros se destacaram por dedicarem mais tempo à venda dos produtos.

Foi possível confirmar com a população entrevistada, que existe uma carência de assistência técnica para orientação de produção, manejo e manutenção das atividades desenvolvidas nos seus lotes. A ausência de assistência técnica interfere, diretamente, na rentabilidade dos sistemas de produção; no nível tecnológico (GUANZIROLI et al. 2001; LIMA et al. 2009) e no desenvolvimento de alternativas de produção em meio as adversidades enfrentadas no dia a dia do produtor. Um dos entrevistados fez menção da realização de análise 
de terra do seu lote há três anos pela Empresa de Assistência Técnica e Extensão Rural - EMATER, todavia, não teve mais qualquer acompanhamento ou auxílio desse órgão nos anos posteriores.

A carência de assistência técnica aos moradores do assentamento pode resultar em ações tomadas pelos assentados que configurem o insucesso de atividades agrícolas produtivas, seja pelo desconhecimento de técnicas e formas adequadas de lidar com o solo e produzir, resultando em terras improdutivas e degradadas. Essa lógica pode resultar na não inserção desses assentados no agronegócio, bem como na ausência de apoio à agricultura familiar (RAMOS et al. 2001). Todavia, é importante destacar que o assentamento existe desde 1997 e os assentados, com suas famílias têm persistido e sobrevivido dessas terras e aplicação de seus conhecimentos agrícolas tradicionais, em alguns casos, há mais de 25 anos.

Dentre os lotes avaliados, $100 \%$ deles apresentam em seus limites, solos do tipo Argissolo Amarelo Distrófico típico. Esse tipo de solo apresenta boas condições físicas de retenção de umidade e boa permeabilidade, fertilidade normalmente baixa, elevada acidez e risco de erosão causada pela diferença de textura superficial e subsuperficial em condições de declividade (SANTOS et al. 2013). A maioria dos entrevistados $(60 \%)$ percebeu processos erosivos nos lotes que apresentam esse tipo de solo. Quanto à textura, existem contradições sobre a percepção entre um tipo de solo arenoso e argiloso.

Um dos lotes avaliados além da predominância de Argissolos, também apresenta solos identificados como Cambissolo Háplico Distrófico típico. Solos dessa ordem, normalmente, estão associados às áreas de relevo muito movimentados (ondulados a montanhosos), fertilidade natural variável, pequena profundidade, susceptíveis a processos erosivos (SANTOS et al. 2013), coincidindo com o relato afirmativo de ocorrência de erosões no local por um dos entrevistados.

Um dos entrevistados relata que o solo do seu lote se apresenta como seco, arenoso no horizonte superficial e amarelado em profundidade. Uma das características do Latossolo Amarelo Distrófico típico é a baixa retenção de água, bem como coloração amarelada (SANTOS et al. 2013), descrição que concorda com a percepção do entrevistado.

Outro entrevistado afirmou que o solo do seu lote é argiloso, seco e amarelo claro. Esse lote está localizado em solos classificados como Nitossolo Vermelho Distrófico típico e Argissolo Amarelo Distrófico típico (SOUZA, 2008). Para o primeiro solo classificado, uma característica relevante e que concorda com a percepção do entrevistado é a textura argilosa do solo e a coloração amarelada vai de encontro à classificação do segundo solo (SANTOS et al. 2013).

O lote de um dos entrevistados apresenta solos do tipo Gleissolo Háplico Distrófico típico, que conforme percepção do mesmo apresenta cor preta, textura argilosa e normalmente ocorre em região alagada. Sua percepção está de acordo com a caracterização desse tipo de solo que compreende solos cuja drenagem varia 
de mal a muito mal drenada e que possuem características resultantes da influência do excesso de umidade permanente ou temporário, devido à presença do lençol freático próximo à superfície, durante um determinado período do ano, com horizonte subsuperficial de coloração acinzentada (SANTOS et al. 2013).

Dentre os entrevistados, $90 \%$ afirmam que o solo de seus lotes poderia ser melhorado de diferentes formas como: "através de análise do solo para saber o que o solo precisa"; "se uma pessoa acompanhasse para plantar mais coisas"; utilizando de técnicas como a marcação de piquetes; trabalhando em curvas de nível; ou ainda "corrigindo o solo". Todas essas afirmações vão ao encontro da necessidade de adubação e correção da fertilidade, características dos solos predominantes na área do assentamento.

Ao serem questionados sobre a dificuldade de trabalhar com o solo de seu lote, $60 \%$ dos entrevistados afirmaram não ter dificuldades alguma para trabalhá-lo. Todavia, problemas foram mencionados como: falta de mão de obra para auxílio no trabalho diário, falta de recursos, distância dos centros urbanos e ainda a declividade do terreno de seus lotes.

A localização de assentamentos em regiões com limitações no quadro natural do local parece ser uma constante, no que diz respeito aos projetos de assentamento (GUANZIROLI et al. 2001; LEITE et al. 2004).

A maioria dos assentados afirma que o solo do seu lote é compactado, relatando situações como: "o chão está seco"; "na época da seca o solo parece um chifre de tão duro"; "qualquer lugar que mexe a terra é dura"; "na parte de cima do morro é só arando, porque antes era criado boi nesse lugar". Para Mantovani (1987), a compactação do solo pode ser considerada à luz de dois fatores: porosidade atrelada à densidade do solo e resistência à penetração, apresentando eventos visuais no solo como formação de crosta, zona compactada de superfície, água empoçada, dentre outros. Reichert et al. (2007) afirmam que a compactação é consequência da ação antrópica.

A distinção dos solos pelos assentados, com base nos aspectos etnopedológicos levantados por eles como: necessidade de correção do solo, noções de compactação do solo, processos erosivos presentes nos lotes, percepção de cor e textura dos solos demonstra a compreensão da realidade local e em alguns casos, concorda com a descrição técnica definida pela EMBRAPA, ratificando que essa percepção é extremamente rica e de uma essência simples e admirável.

\section{CONCLUSÕES}

O perfil dos assentados e de seus lotes aponta para pessoas com idade superior a 50 anos, baixo nível de escolaridade, carentes de assistência técnica para auxiliar no desenvolvimento de suas atividades, baixo nível tecnológico aplicado em seus lotes, seja para a produção agrícola, seja para a pecuária, pouca ou 
nenhuma especialização e predominância de mão de obra familiar. Quanto à percepção dos aspectos etnopedológicos dos assentados ressalta-se a semelhança na descrição dos solos presentes no lote avaliado, em uma linguagem simplista e popular com aquela definida pela literatura científica e acadêmica. São de relevante importância a compreensão tradicional dos solos e sua valorização junto ao meio científico, como um subsídio para uma abordagem mais integrada sobre os solos presentes no país.

\section{REFERÊNCIAS}

ALVARES, C. A.; STAPE, J. L.; SENTELHAS, P. C.; GONÇALVES, J. L. M.; SPAROVEK, G. Köppen's climate classification map for Brazil. Meteorologische Zeitschrift, v. 22, n. 6, p. 711-728, 2013. Disponível em: <http://www.lerf.eco.br/img/publicacoes/Alvares etal 2014.pdf>. Acesso em: 15 ago/2018. DOI: 10.1127/0941-2948/2013/0507.

ARAÚJO, A. L.; ALVES, A. G. C.; ROMERO, R. E.; FERREIRA, T. O. Etnopedologia: uma abordagem das etnociências sobre as relações entre as sociedades e os solos. Ciência Rural, v.43, n.5, p.854-860, mai, 2013. Disponível em:

$<$ http://www.redalyc.org/articulo.oa?id=33126308016>. Acesso em: 07 ago/2018.

CARDEL, L. M. P. S.; OLIVEIRA, R. A. Práticas e Contradições: um estudo de caso sobre camponeses assentados no médio São Francisco. Revista de Economia e Sociologia Rural, v. 51, № 4, p. 625-644, Out/Dez, 2013. Disponível em: <http://www.scielo.br/pdf/resr/v51n4/a01v51n4.pdf>. Acesso em: 23 ago/2018.

DAL MORO, M. Agricultura familiar e áreas protegidas: desafios para as políticas de proteção social e ambiental. III Jornada Internacional de Políticas Públicas, São Luís - MA, p. 1-9, 2007. Disponível em: < http://www.joinpp.ufma.br/jornadas/joinpplll/html/Trabalhos/EixoTematicol/Eixo9\%20\%20e4fb733d38052e22e3daMaristela\%20D al\%20Moro.pdf> Acesso em: $13 \mathrm{abr} / 2018$.

DE GASPARI, L. C.; KHATOUNIAN, C. A. Características das famílias, estruturação da produção e estratégias de comercialização em um assentamento de Reforma Agrária. Revista de Economia e Sociologia Rural, v. 54, № 02, p. 243-260, Abr/Jun 2016. Disponível em: <http://www.scielo.br/pdf/resr/v54n2/1806-9479-resr-54-02-00243.pdf>. Acesso em: 02 ago/2018. DOI: 10.1590/1234.56781806947900540203.

FERNANDES, T. A. G.; LIMA, J. E. Uso de análise multivariada para identificação de sistemas de produção. Pesquisa Agropecuária Brasileira, v.26, n.10, p.1823-1836, 1991. Disponível em: <https://seer.sct.embrapa.br/index.php/pab/article/view/3531/864>. Acesso em: 13 set/2018.

GUANZIROLI, C.; ROMEIRO, A.; BUAINAIN, A. M.; SABBATO, A. D.; BITTENCOURT, G. Agricultura Familiar e Reforma Agrária no Século XXI. 1. ed. Rio de Janeiro: Garamond, 2001. 288 p.

IBGE. Instituto Brasileiro de Geografia e Estatística. População residente. 2010. Disponível em: <https://sidra.IBGE.gov.br/tabela/202\#resultado>. Acesso em: $14 \mathrm{mar} / 2018$.

IBGE. Instituto Brasileiro de Geografia e Estatística. Produção agrícola e pecuária municipal. 2016. Disponível em: <https://www.IBGE.gov.br/estatisticas-novoportal/economicas/agricultura-e-pecuaria.html>. Acesso em: 14 mar/2018.

INEA. Instituto Estadual do Ambiente. Elaboração do Plano Estadual de Recursos Hídricos do Estado do Rio de Janeiro. R2 - F Caracterização Ambiental, Mar - 2014. Disponível em:

<http://www.inea.ri.gov.br/cs/groups/public/documents/document/zwew/mdyv/ edisp/inea0062133.pdf>. Acesso em: 13 ago/2016.

INCRA. Instituto Nacional de Colonização e Reforma Agrária. 2009. Projeto de Assentamento da Fazenda do Salto. Impresso. Set/2009.

INCRA. Instituto Nacional de Colonização e Reforma Agrária. 2012. Disponível em: <http://www.INCRA.gov.br/rj-INCRA-entregacontratos-de-concessao-de-uso-em-barra-mansa>. Acesso em: 12 ago/2016.

INCRA. Instituto Nacional de Colonização e Reforma Agrária. 2013. Sistema Nacional de Cadastro Rural - Índices básicos de 2013. Disponível em: <http://www.INCRA.gov.br/sites/default/files/uploads/estrutura-fundiaria/regularizacao-fundiaria/indicescadastrais/indices basicos 2013 por_municipio.pdf> Acesso em: 20 mai/2018. 
INCRA. Instituto Nacional de Colonização e Reforma Agrária. 2017. Disponível em: <http://painel.INCRA.gov.br/sistemas/index.php>. Acesso em: $13 \mathrm{abr} / 2018$.

JÚNIOR, G. B. M.; BARIONI, L. G.; VILELA, L.; BARCELLOS, A. O. Área do piquete e taxa de lotação no pastejo rotacionado. Planaltina DF: Embrapa Cerrados, 2003. 8 p. Disponível em: <https://www.infoteca.cnptia.embrapa.br/bitstream/doc/569854/1/comtec101.pdf>. Acesso em: 10 jul/2018.

LEITE, S.; HEREDIA, B.; MEDEIROS, L.; PALMEIRA, M.; CINTRÃO, R. Impactos dos Assentamentos: um estudo sobre o meio rural brasileiro. Brasília: Instituto Interamericano de Cooperação para a Agricultura: Núcleo de Estudos Agrários e Desenvolvimento Rural; São Paulo: Editora UNESP, 2004. 392 p.

LIMA, P. de O.; DUARTE, L. S.; SOUZA, A. Z. B. de; AQUINO, T. M. F. de; OLIVEIRA, C. S. de. Perfil dos produtores rurais do município de Quixeramobim no estado do Ceará. Revista Caatinga, v.22, n.4, p.255-259, out.-dez. 2009. Disponível em: $<$ https://periodicos.ufersa.edu.br/index.php/caatinga/article/view/1389>. Acesso em: 10 jul/2018.

LIMA, K. K. S. de; LOPES, P. F. M. A qualidade sócio ambiental em assentamentos rurais do Rio Grande do Norte, Brasil. Ciência Rural, Online, set. 2012. Disponível em: <http://www.scielo.br/pdf/cr/2012nahead/a35012cr6970.pdf>. Acesso em: 14 mai/2018.

LOPES, L. G. R.; CARVALHO, D. B. Dinâmica temporal do assentamento e os projetos de vida da juventude rural. Revista de Economia e Sociologia Rural, v. 53, № 04, p. 571-588, Out/Dez, 2015. Disponível em: <http://www.scielo.br/scielo.php?pid=S010320032015000400571\&script=sci abstract>. Acesso em: 20 jun/2018. DOI: 10.1590/1234-56781806-9479005304001.

LUMBRERAS, J. F., et. al. Zoneamento Agroecológico do Estado do Rio de Janeiro. Rio de Janeiro: Embrapa Solos, 2003.113 p. Disponível em: <https://rigeo.cprm.gov.br/jspui/bitstream/doc/458/1/bol_33_2003_zon_rj.pdf>. Acesso em: 26 nov/2017.

MANTOVANI, E. C. Compactação do solo. Informe Agropecuário, Belo Horizonte, v. 13, n. 147, p. 52-55, mar, 1987. Disponível em: <https://ainfo.cnptia.embrapa.br/digital/bitstream/item/66338/1/Compactacao-solo.pdf>. Acesso em: 03 mar/2018.

RAMOS, D. P.; ASSIS, D. S.; SANTOS, M. L. M.; MANZATTO, C. V.; DA COSTA, J. R. P. F. O Assentamento como Indutor do Desenvolvimento Agrícola Sustentável - Um Novo Modelo de Reforma Agrária para o País. Rio de Janeiro: Embrapa Solos, 2001. 23p. (Embrapa Solos. Documentos; n.23).

REICHERT, J. M.; SUZUKI, L. E. A. S.; REINERT, D. J. Compactação do solo em sistemas agropecuários e florestais: identificação, efeitos, limites críticos e mitigação. Tópicos Ciência do Solo, v. 5, p. 49-134, 2007. Disponível em: <http://fisicadosolo.ccr.ufsm.quoos.com.br/downloads/Producao Artigos/2007 Topicos.pdf>. Acesso em: 14 jul/2018.

ROSANOVA, C.; RIBEIRO, D. de C. Caracterização socioeconômica dos produtores de leite da agricultura familiar e análise da informalidade no município de Palmas/TO. 2010. Disponível em: <http://connepi.ifal.edu.br/ocs/index.php/connepi/CONNEPI2010/paper/

viewFile/1747/46>. Acesso em: $10 \mathrm{mar} / 2018$.

SANTOS, A. D.; FARIA, A. L. D.; LEITÃO, A. P. S. D. M.; MATTOS, C. B.; MÁXIMO, F. A.; DANTAS, J. O.; OLIVEIRA, L. H. M.; QUEIROS, L. R.; SOUZA, M. I. F.; PEREIRA, R. M.; PONTES, S. D. C. L. D. Empresa Brasileira de Pesquisa Agropecuária. Ageitec - Agência Embrapa de Informação Tecnológica. Árvore do Conhecimento - Solos Tropicais. 2013. Disponível em: <http://www.agencia.cnptia.embrapa.br/gestor/solos tropicais/Abertura.html>. Acesso em: 10 mar/2018.

SOARES, S. de O.; OAIGEN, R. P.; BARBOSA, J. D.; OlIVEIRA, C. M. C.; ALBERNAZ, T. T.; DOMINGUES, F. N.; MAIA, J. T. da S.; CHRISTMANN, C. M. Perfil dos produtores de leite e caracterização técnica das propriedades leiteiras dos municípios de Rondon do Pará e Abel Figueiredo, Estado do Pará. Veterinária em Foco, v. 10, n. 2, p. 159-168, jan/jun 2013. Disponível em: $<$ http://www. periodicos.ulbra.br/index.php/veterinaria/article/view/1145>. Acesso em: 14 jul/2018.

SOSA, B. M.; JAIME, A. M. R.; LOZANO, D. R. A.; ROSSET, P. M. Revolução Agroecológica - 0 movimento de camponês a camponês da ANAP em Cuba. 1. Ed. no Brasil: Asociación Nacional de Agricultores Pequeños y La Vía Campesina, 2011.

SOUZA, J. M. P. F. Relatório do Levantamento Semi Detalhado dos Solos do Perímetro do P.A. Fazenda Do Salto, Barra Mansa-RJ. Rio de Janeiro: INCRA, 2008, $40 \mathrm{p}$. 